\title{
PERAN BAIT MAL DALAM JAMINAN SOSIAL DI ERA FIKIH KLASIK
}

\author{
F. Setiawan Santoso \\ Dosen FAI-UCY \\ fattah_ss@yahoo.com
}

\begin{abstract}
This study intends to explore bait al-mal as the principal of financial institution in Islam within the view of fikih muamalah and the history of bait al-mal in the era of classical jurisprudence in order to get clarity about the role of government in social security, especially that developed in Andalusia. Management of bait al-mal has clarified the role of the government as a mandate of God's Right. Utilization of God's right other than for Him alone, also expanded for the benefit of public altogether. Social security system in Islam has implemented it both in its muamalah fiqh and its economic history. All of that is based on the government's obligation to engage in social security system to guarantee law enforcement in all aspects of life and maintenance of economic and political stability.
\end{abstract}

Keywords: role, bait al-mal, social security, fiqh classic

\begin{abstract}
Abstrak: Penelitian ini bermaksud menggali bait mal sebagai lembaga keuangan pokok dalam Islam secara fikih muamalah dan sejarah bait mal di era fikih klasik guna mendapatkan kejelasan tentang peran pemerintah dalam jaminan social, khususnya yang berkembang di Andalusia. Pengeloaan bait mal telah memperjelas peran pemerintah sebagai sebagai pemegang mandat Hak Allah. Pemanfaatan Hak Allah selain memang untuk-Nya semata, juga diperluas bagi kemaslahatan umat secara bersama. Sistem jaminan social dalam Islam telah mengimplementasikan hal itu baik dalam fiqh muamalah maupun sejarah perekonomiannya. Semua itu didasari dengan keharusan pemerintah terlibat dalam sistem jaminan sosial guna jaminan penegakan hukum di semua aspek kehidupan dan pemeliharaan stabilitas ekonomi dan politik.
\end{abstract}

Kata kunci: peran, bait mal, jaminan social, fikih klasik

\section{A. Pendahuluan}

Dalam Islam, kebutuhan dasar hidup juga dipandang mutlak untuk mencapai kesejahteraan. Kebutuhan itu mencakup materi dan realisasi 
nilai-nilai spiritual Islam pada kehidupan individu dan masyarakat secara seimbang. ${ }^{1}$

Secara implisit, Rasulullah juga telah memberikan teladan agar pemerintah memenuhi kebutuhan dasar warganya. Menurutnya, anak yang ditinggal mati ayahnya (yatim diasuh negara, dan harta yang ditinggalkan pewaris menjadi hak ahli waris. ${ }^{2}$ Khalifah 'Umar ibn alKhattab bersedekah kepada pengemis Yahudi tua dan membebaskannya dari jizyah. ${ }^{3}$

Para ulama mazhab di era klasik di berbagai mazhab seperti Ibn Hazm, al-Gazali, asy-Syatibi dan an-Nawawi juga telah sepakat bahwa pemenuhan kebutuhan dasar manusia itu fard kifayah, ${ }^{4}$ yang direpresentasikan oleh negara. Dari mereka ini, yang menjabarkan jaminan sosial sebagai instrumen pemenuhan kebutuhan dasar manusia secara komprehensif dilakukan oleh Ibn Hazm, salah satu tokoh penting dalam fikih klasik bermazhab Dahiri, yang hidup di Andalusia saat umat Islam menghadapi kesulitan ekonomi yang parah akibat perang saudara (fitna) pada sekitar tahun 384 H. / 994 M.- 456 H. / 1056 M.5 Hal itu dimungkinkan mengingat ia mempunyai pengalaman praktis dibidang kenegaraan di masa-masa akhir dinasti Umayyah di Andalusia. ${ }^{6}$

Keunggulan system jaminan social Islam yang diajukan oleh Ibn Hazm diuraikan oleh Wartini. Ia mengkaji relevansi konsep BPJS dan jaminan sosial dalam pandangan Ibnu Hazm. Dengan tekanan analisis pada zakat, ia menyimpulkan bahwa Ijtihad Ibnu Hazm lebih liberal dengan berpendapat bahwa kalangan elit dan kaya raya yang bertanggung jawab dalam menjamin sosial bagi kalangan orang miskin. Hukum Zakat

\footnotetext{
${ }^{1}$ M. Umar Chapra, "The Islamic Welfare", h. 198; F. Setiawan Santoso, "Reformasi Ekonomi Berbasis Bagi Hasil Belajar Dari Sistem Ekonomi Sosialis," MUQTASID Jurnal Ekonomi Dan Perbankan Syariah IAIN SALATIGA, 193-207

${ }^{2} A b \bar{u}$ 'Ubaid al-Qāsim ibn Salām, Kitāb al-Amwāl (Beirut: Dār al-Fikr, 1988/1408), h. 236.

3 Abū Yūsuf, Kitāb al-Kharāj (ttp.: Dār al-Iṣlāh li an-Nasr, 1978/1398 h. 126.

${ }^{4} \mathrm{Abū}$ Ishāq ash-Shatibi, al-Muwāfaqāt (Beirut: Dār al-Ma'rifah, tt., II : 177; Yahyā ibn Sharf ad-Dīn an-Nawawi, Minhāj at-Ṭālibīn wa 'Umdah al-Muftīn (Mesir: Dār Ihyā' al-Kutub al-'Arabiyyah, 1343), h. 125; Abū Muhammad ibn 'Alī ibn Ahmad ibn Sa'īd ibn Hazm, al-Muhallā (Beirut: Dār al-Āfāq al-Jadīdah, tt.), IV: 156.

5B. Lewis dkk., The Encyclopaedia of Islam, New Edition (Leiden: E. J. Brill, 1986), h. 790.

${ }^{6}$ Ibid.
} 
telah diperluas melalui pendekatan Dahiri yang tekstualis dan berbeda dengan jumhur. Wartini kemudian merekomendasikan pandangan Ibn Hazm guna mengkritisi BPJS yang berkembang di Indonesia yang dalam satu platform yang berpijak pada jaminan sosial bagi kalangan orang tidak mampu.7 Syufa'at kemudian menjelaskan bahwa tujuan dari keterlibatan pemerintah dalam jaminan social dalam Islam dalam Pemikiran Ibn Hazm adalah menciptakan keadilan ekonomi dan kesejahteraan social. Ia menjabarkan bahwa instrument jaminan social terdiri dari zakat langsung dari masyarakat, pajak yang masuk baitul mal serta mal mustafad yang sepadan dengan kewajiban kepada fakir miskin selain zakat. ${ }^{8}$

Pemasukan baitul Mal tidak sebatas pajak, namun beraneka ragam. Penggunaannya juga tidak terbatas bagi penjaminan social semata. Kajian pengelolaan bait Mal dalam penjaminan Sosial kemudian menjadi penting guna menjelaskan sejauh mana fungsi pemerintah dalam mensejahterakan kehidupan social ekonomi umat, terutama dalam penjaminan sosial.

Penjelajahan pemikiran Ibn Hazm terhadap implementasi jaminan social mencakup pelaksanaannya pada kondisi ekonomi negara berada di posisi yang terendah seperti yang dirasakan saat ia terlibat praktis dalam pemerintahan dinasti Umayyah di Andalusia. Hal ini menjadi signifikan bagi sebagaian besar negara-negara muslim pada masa sekarang yang mengalami kondisi yang sama. ${ }^{9}$ Sedangkan pemikir dan praktisi hokum ekonomi tidak merekomendasikan sebagian pola sistem jaminan sosial yang ada sekarang ini bagi negara-negara yang kondisi ekonominya demikian. ${ }^{10}$

7 Atik Wartini, "Jaminan Sosial Dalam Pandangan Ibnu Hazm Dan Relevansinya Dengan Pengembangan Jaminan Sosial Di Indonesia," Hunafa: Jurnal Studia Islamika Vol. 11, No. 2, Desember 2014: 245-275

${ }^{8}$ Syufaat, Fikih Jaminan Sosial dalam pespektif Ibn Hazm (994-1064), Manahaij, Volume IX, Juni 2015, 111-122.

9 Pada tahun 1998, UNDP mengelompokkan 21 negara muslim muslim atau sekitar 44\% dari 44 negara anggota Perserikatan Bangsa-Bangsa (PBB dalam negara yang kurang berkembang (Least Developed. Organisasi negara-negara Islam (OKI menyebutkan bahwa 33 atau $67 \%$ dari total 56 negara anggotanya termasuk negara kurang berkembang dan berpendapatan rendah (Low Income Countries. Nabil Md. Dabour, "Poverty And Food Insecurity In The Least Developed And Low-Income OIC Member Countries", dalam Journal of Economic Cooperation 22, 2 (2001) 99-13

${ }^{10}$ Sri Tua Arif, "Kebutuhan Dasar", h. 466-467 
Upaya penggalian pemikiran ulama klasik seperti Ibn Hazm dari Andalusia tentang sistem jaminan sosial dapat menjadi alternatif bagi negara-negara muslim. Ibn Hazm secara tegas menghendaki pemerintah untuk bertindak aktif dalam jaminan sosial dan bersikap keras memaksa warga yang kaya untuk menolong warga miskin. Menurutnya;

Diwajibkan bagi orang-orang kaya setiap negara untuk menyantuni kaum miskinnya. Pemerintah berhak memaksa mereka apabila zakat dan mal muslimin tidak dapat memenuhi kebutuhan mereka. Agniya' harus memberikan kebutuhan pangan yang pokok, sandang untuk menghindarkan dari bahaya perubahan musim, dan tempat tinggal yang melindungi mereka dari derasnya hujan, sengatan matahari dan penglihatan orang yang lewat. ${ }^{11}$

Dari sisi pengembangan fikih muamalah, Penggalian jaminan social di Andalusia bersama fikih Ibn Hazm dapat menjadi sumbangan bagi seruan revivalisme yang dikenal pula dengan istilah tajdid. Semangat ini berupa gerakan kembali kepada semangat dan ruh Islam, al-Quran dan sunnah secara nyata dalam kehidupan personal ataupun kolektif umatnya. ${ }^{2}$

Selain itu, kajian demikian bisa juga berpengaruh pada modifikasi instrumen ekonomi yang ada menuju persesuaian syariah. Perekmbangan pesat dunia ekonomi telah melahirkan banyak alternative bagi pemenuhan kebutuhan hidup bagi kelas yang berkekurangan. Meski demikian, pendalaman dimensi syariah di dalamnya akan memberikan kenyamanan pesertanya yang beragama Islam. Salah satu yang bisa dipertimbangkan adalah modal ventura. ${ }^{13}$

\section{B. Metode Penelitian}

Penelitian ini bermaksud menggali bait mal sebagai lembaga keuangan pokok dalam Islam secara fikih muamalah dan sejarah bait mal di era fikih klasik guna mendapatkan kejelasan tentang peran pemerintah dalam jaminan sosial. Kombinasi norma fikih dan sejarah social ekonomi

${ }^{11} \mathrm{Abu}$ Muhammad ibn 'Ali ibn Ahmad ibn Sa'id ibn Hazm, al-Muhalla, (Beirut: Dar al-Afaq al-Jadidah, tt., VI : 156.

${ }^{12}$ Fikrec Karcic, Applying The Shariah in Modern Societies, Main Development and Issues, Islamic Studies vol. 140 Summer 2001 no. 2, h. 215; Abdullah Saeed, Islamic Banking and Interest, A Study of The Prohibiting of Riba and its Contemporary Interpretation, (Leiden-New York-Koln: EJ Brill, 1996, h. 5-6.

13 F. Setiawan Santoso, "Reformasi Ekonomi Berbasis Bagi Hasil Belajar Dari Sistem Ekonomi Sosialis,” Jurnal Ulumuddin Voleume 2 Nomor 5, Desember 2015, 3850 
membutuhkan focus wilayah yang spesifik bagaimana baitul mal itu berperan dalam jaminan social. Oleh karena itu, tulisan secara spesifik membahas pemikiran Ibn Hazm yang memiliki keunggulan wawasan fikih dan kenegaraan secara teoritis dan praktis di masa-nya didukung dengan pemikiran ulama sebaya yang sama-sama hidup di Andalusia.

Penelitian demikian menguatkan hasil penelitian dari Yazwardi tentang perkembangan pemikiran Ibn Hazm. Pilihannya pada mazhab Dahiri sangat dipengaruhi oleh faktor-faktor sosial yang melingkupi hidupnya; yaitu kondisi sosial politik dan keagamaan di Andalusia yang dilanda oleh kemelut politik dan perpecahan umat Islam. Dukungan para ulama Maliki yang mayoritas cenderung pada legitimasi kekuasaan dan perilaku para penguasa Umayyah kontras dengan pendekatan Dahiri. Dalam menghadapi perubahan sosial, Ia mempergunakan metode istidlal dengan konsep Dalil, yang secara konsepsional tidak sama dengan qiyas. Namun, substansinya hampir sama. Jadi, Ibnu Hazm juga tidak kaku atau asosial dalam menghadapi perubahan sosial. ${ }^{14}$

Kombinasi kajian fikih dan sejarah social ekonomi ini kemudian mengandalkan investigasi literatur sebagai pokok pengumpulan datanya. Penulisannya diawali dengan penjelasan teoritis tentang pemerintah dan kebutuhan dasar manusia. Kebutuhan itulah yang menjadi dasar bagi pelaksanaan system jaminan social. Pembahasan selanjutnya adalah baitul mal, baik dari sisi penerima, pengeluaran dan pengelolaannya yang tidak bisa lepas dari tangan pemerintah. Semua uraian diatas kemudian ditutup dengan analisis peran pemerintah yang terungkap dalam penjelasan fikih dan sejarah bait mal.

\section{Negara dan kebutuhan Dasar manusia}

1. Pemerintah dalam Fiqh Klasik

Pandangan Ibn Hazm tentang negara menganut paham integralistik yang berpendirian bahwa emerintahan negara diselenggarakan atas dasar "kedaulatan Ilahi" (divine sovereignty dan konstitusi adalah wahyu-Nya (syari'ah karena kedaulatan itu memang

${ }_{14}$ Yazwardi, Pengaruh Perubahan Sosial Terhadap Pemikiran Literalism Ibnu Hazm, AN NISA'A, Vol. 9, No. 2, Desember $2014: 61-80$ 


\section{F. Setiawan Santoso}

berasal dari dan berada di tangan Tuhan. ${ }^{15}$ Agam Islam adalah sebuah totalitas yang padu bagi pemecahan terhadap berbagai permasalahan kehidupan sosial, ekonomi dan politik. agama bukanlah semata-mata menyangkut hubungan antara manusia dan Tuhan, melainkan suatu agama yang sempurna dan lengkap dengan pengaturan bagi segala aspek kehidupan manusia, termasuk kehidupan bernegara. Islam selalu hadir di mana-mana (omnipresence melayani dan memberikan panduan umatnya yang benar dalam bertindak. ${ }^{16}$

Paham integralistik ini mirip dengan yang ini dianut oleh kelompok Syi'ah. Paradigma politik Syi'ah memandang bahwa negara (Imamah adalah lembaga keagamaan dan kenegaraan. Legitimasi negara berasala dari doktrin-doktrin Wahyu Tuhan dan diturunkan lewat garis keturunan Nabi Muhammad S.a.w., ${ }^{17}$ Paradigma Syi'ah menekankan walayah (kecintaan dan pengabdian kepada Tuhan dan ismah (kesucian dari dosa, yang hanya dimiliki oleh para keturunan Nabi yang berhak untuk menjadi kepala negara. ${ }^{18}$

Dalam pemilihan khalifah atau imam, Ibn Hazm juga mengajukan kriteria yang mirip dengan apa yang dikehendaki oleh penganut Syi'ah, pemimpin negara hendaknya dipilih dari keturunan kaum Quraisy dan memiliki karakter menjauhkan diri dari perilaku dosa besar atau kecil. Walapun begitu, ia masih seperti para ulama Sunni pada umumnya yang menekankan ijma' (permufakatan dan bai'ah (pembai'atan sebagai alat legitimasi bagi khalifah yang terpilih.

Hubungan yang integral antar agama dan negara ini berlawanan dengan pandangan para ulama yang mendukung hubungan simbiotik antara keduanya dimana agama dan negara berhubungan secara timbal-

15 M. Din Syamsuddin, "Usaha Pencarian Konsep Negara dalam Sejarah Pemikiran Politik Islam”, dalam Ulumul Qur'an, No. 2, Vol. IV, Tahun 1993, h. 5.

${ }_{16}$ Lihat Bahtiar Effendi, Islam dan negara Transformasi Pemikiran dan Praktik Politik Islam di Indonesia, (Jakarta : Paramadina, 1998, cet. ke-1, p. 6-7. Lihat juga David Waines, An Introduction to Islam, (New York : Cambridge University Press, 1995, cet. ke1, p. 243. Pendapat senada juga pada, John L. Esposito (edts, Islam And Development Religion And Sociopolitical Change, (New York : Sylacuse University Press, 1980, cet. ke1, p. ix.

17 Ibid.

${ }^{18}$ Hamid Enayat, Modern Islamic Political Thought, ( Austin: IIIT,1982) h. 6. 
balik dan saling memerlukan. ${ }^{19}$ Syari'at Islam menuntut adanya negara bagi umat Islam demi terlaksananya ajaran-ajaran Islam dalam masyarakat. ${ }^{20}$ Namun Islam tidak meletakkan suatu pola yang baku tentang teori kenegaraan yang harus dijalankan oleh masyarakat (Muslim, sistem politik agama Islam tidak mempunyai sistem politik tertentu dan hanya memiliki seperangkat tata nilai etis yang dapat dijadikan sebagai pedoman penyelenggaraan negara. ${ }^{21}$ Ajarannya tidak menentukan suatu kerangka sistem pemerintahan tertentu bagi kaum Muslim, karena logika tentang kesesuaian agama ini untuk sepanjang masa dan tempat menuntut agar soal-soal yang selalu akan berubah oleh kekuatan evolusi harus diserahkan kepada akal manusia, dibentuk menurut kepentingan umum dan dalam rangka prinsip-prinsip umum yang telah digariskan oleh agama ini. ${ }^{22}$

Pada satu sisi, penganut paham simbiosis masih memandang negara seperti para ulama mazhab integral. pemikiran Abu Ya'la (w. 1058 M. dalam karyanya yang berjudul sama dengan buku hasil susunan alMawardi, al-Ahkam as-Sultaniyyah, menegaskan bahwa konsep negara tidak dapat diketahui kecuali dari wahyu-Nya, penguasa adalah bayangan Tuhan di muka bumi untuk meneruskan misi kenabian guna memelihara agama dan mengatur dunia.23 Abu Ya'la menganggap bahwa penegakan negara merupakan tugas suci yang dituntut agama sebagai salah satu perangkat untuk mendekatkan manusia kepada Allah, syari'ah menempati posisi sentral sebagai sumber legitimasi terhadap realitas politik dan berperan besar dalam penegakan hukum.

Meski demikian Abu Ya'la tidak memandang akhlak dan perilaku khalifah memiliki urgensi dalam pertanggungjawaban pemerintahan, imam yang berkhianat atau meminum khamr masih layak memimpin

19 Ibid.

${ }_{20}$ Ahmad Azhar Basyir, Refleksi atas Persoalan Keislaman: Seputar Filsafat, Hukum, Politik dan Ekonomi, (Bandung: Mizan, 1993, h. 55.

${ }^{21}$ Munawir Sjadzali, Islam dan Tata Negara: Ajaran, Sejarah dan Pemikiran, h. 233 .

${ }^{22}$ Effendi, Islam dan, h. 13

23 Ya'la, al-Ahkām as-Sultāniyyah, (Beirut: Dār al-Fikr, t.t.), h. 5 . 


\section{F. Setiawan Santoso}

negara, harus dibela dan diikuti perintahnya.24 Pendirian Ibn Taimiyah, termasuk pendukung paham simbiotik, lebih ekstrim, keberadaan kepala negara, meskipun zalim, lebih baik bagi masyarakat dari pada mereka harus hidup tanpa adanya pengendali negara. ${ }^{25}$

2. Kebutuhan Dasar Manusia

Ibn Hazm sendiri menetapkan bahwa hajat pokok yang perlu diberikan bagi fakir miskin adalah pangan yang menjadi kebutuhan wajib, sandang yang mampu melindungi dari serangan hawa musim panas dan dingin, serta tempat tinggal yang dapat melindungi privasi penghuninya dari pandangan orang lain. ${ }^{26}$ Terhadap kebutuhan sandang dan pangan, Ibn Hazm dapat menggalinya dari nass tentang wajibnya santunan bagi kebutuhan kaum fakir tersebut. Sedangkan kebutuhan papan, ia berargumen bahwa kebutuhan tersebut merupakan penyesuaian dengan tingkat pendapatan dan kondisi sosial ekonomi umat. ${ }^{27}$

Dengan demikian penentunan kebutuhan dasar ini dapat berkembang dan berubah sesuai dengan perkembangan kesejahteraan dan kebutuhan ekonomi masyarakat. Ibn Hazm sendiri memprioritaskan pada aspek pendukung keimanan sebagai kebutuhan dasar setelah pangan, pakaian dan tempat tinggal. Menurutnya, Allah SWT tidak melarang sedekah bagi setiap perbuatan baik dengan mendasarkan pada riwayat Ibn 'Abbas yang tidak melarang haji dengan biaya berasal sedekah dan zakat, juga penggunaannya untuk pembebasan budak. ${ }^{28}$

Pengembangan kebutuhan dasar ini berbeda dengan yang dianut oleh al-Gazali (w. 550 H) dan an-Nawawi (w.650 H.) maupun Al-Gazali menetapkan pengobatan sebagai kebutuhan dasar setelah sandang, pangan dan papan meski dalam tingkat minimum. Setelah itu, kebutuhan penunjang iman dan ibadah baru dapat ditetapkan. ${ }^{29}$ Sependapat al-

24 Ibid.

25 Ibid., h. 174

${ }^{26}$ Ibid.

${ }^{27}$ Ibid. VIII: 123.

${ }^{28}$ Ibid., X: 88

29 Al-Gazali, Al-Iqtisad fi al-I'tiqad, (Beirut: Dar al-'Amanah, 1969), h. 1969 
Gazali, an-Nawawi menyebutkan bahwa pengobatan bagi fakir miskin menjadi tanggung jawab negara.30

Aturan hukum yang jelas dan pasti sangat bermanfaat bagi semua yang terlibat. Pemerintah mempunyai kewajiban untuk melaksanakan tugasnya secara benar, fakir merasa terlindungi hak-haknya dan kelompok kaya merasa tidak tertindas dengan kewajiban dan kontrol pemerintah terhadap partisipasi mereka dalam jaminan sosial. Unsur yang penting ini seharusnya juga terlihat dalam mekanisme distribusi yang Ibn Hazm ajukan.

Salah satu hak fakir miskin adalah santunan kebutuhan dasarnya. Bagi kelompok fakir miskin, perbedaan ini berimplikasi pada santunan yang diberikan. Kelompok miskin hanya dibantu sebatas kebutuhan yang seharusnya ia cukupi dengan kekayaannya sendiri. ${ }^{31}$ Fakir dianggap tidak mampu, maka ia memerlukan bantuan lebih banyak daripada kelompok miskin untuk mencukupi kebutuhan. Bahkan bantuan bisa diberikan dalam jumlah yang tidak terbatas karena Ibn Hazm tidak membatasi jumlah atau waktu tertentu yang harus dipenuhi. ${ }^{2}$

Santunan ini dapat pula diberikan secara langsung atau tidak. Bagi miskin, santunan diutamakan berupa bantuan tidak langsung seperti penciptaan lapangan kerja yang hasilnya dapat mencukupi sendiri sepanjang hidup hingga mereka mampu membayar zakat. Sementara bagi fakir yang cacat tubuh atau lanjut usia atau janda yang tidak mampu bekerja, santunan diberikan berbentuk transfer secara langsung berupa uang atau pangan. Sementara fakir yang sehat, selain santunan kebutuhan pokok juga disertai pemberian kerja yang dapat dijadikan sebagai sumber nafkahnya.

Selain kejelasan santunan yang diberikan, Kebutuhan dasar yang menjadi santunan bagi fakir secara langsung juga harus dipastikan, yaitu kebutuhan yang dapat diterima secara nalar dan obyektif dapat mengatasi kondisi darurat mengingat kondisi ini juga harus diketahui oleh nalar

${ }^{30}$ Yahya ibn Syarf ad-Din an-Nawawi, Minhaj at-Talibin wa 'Umdah al-Muftin, (Mesir: Dar Ihya' al-Kutub al'Arabiyyah, 1343), h. 125.

${ }^{31}$ Ibn Hazm, Al-Muhalla, V: 148, 152

${ }^{2}$ Ibid. V: 156 
seperti yang telah oleh Ibn Hazm tentang hukum darurat. Kebutuhan tersebut harus pasti, dikenal dan dibutuhkan oleh masyarakat secara umum sehingga dapat menjadi alasan yang membolehkan pemenuhannya dengan cara-cara haram.

\section{Bait mal dalam Jaminan Sosial}

Pemasukan negara di masa Andalusia tidak jauh berbeda dengan apa yang telah dipraktekkan oleh Rasulullah saw., seperti penarikan pajak dari umat yang didasarkan pada keyakinan agama yang dianut oleh wajib pajak. Pemasukan negara mengandalkan zakat, kharaj, jizyah, ganimah, khums, dan pajak eksport import. 33 Harta ini sama maknanya dengan mal Allah, setiap harta yang tidak diketahui pemiliknya dan telah menjadi milik seluruh umat. 34

Harta Tuhan itu juga dinamakan mal muslimin karena pemanfaatan bagi kepentingan umum dan dikelola melalui lembaga bait mal. Eksistensi bait al-mal sebagai institusi keuangan pemerintah yang konkrit dalam Islam sangat sulit dilacak. Abu Ya'la, salah satu tokoh mazhab Hanbali, menegaskan bahwa penelusuran bait al-mal sebagai institusi (al-makan tidak dimungkinkan tetapi keberadaan lembaga ini dapat diketahui dari orientasinya (jihah. 35

Setelah dimasukkan dalam khizanat al-mal yang fungsinya sama dengan bait al-mal menjadi pendapatan pemerintah yang digunakan untuk kepentingan publik.36 Oleh karena itu Pengelolalan bait al-mal dipisahkan dari kekayaan yang berstatus hak milik pribadi khalifah (Mal Khas. Pemasukan yang termasuk dalam Mal Khas diperoleh dari tanah-

33 Pedro Chalmeta, "An Approximate of The Economic of Andalusia” dalam Salma Khadra Jayyusi, Eds., The Legacy of Muslim Spain, (Leiden-New York-Koln: EJ. Brill, 1994, II: 741.

34 Ibn Hazm, al-Muhalla, VIII: 236

35Abu Ya'la Muhammad ibn al-Hassan al-Farra'i, al-Ahkam as-Sultaniah, (Beirut: Dar al-Fikr, 1406H/1968 M, h. 251;

36Imaduddin menggunakan istilah bait al-mal, tapi ia menjelaskan bahwa departemen yang mengelola dipimpin oleh khazin/ sahib al-khizanah. Ia juga menyebut bait al-mal lain yang khusus bagi pengelolaan harta wakaf, harta anak yatim dan gila. Sedang Chalmetta menyebutnya khizanat al-mal. Heffening menyatakan bait al-mal di Andalusia mengelola wakaf yang kontras dengan khizanat al-mal. Imaduddin, Arab Muslim, h. 100 dan 104; Chalmeta, "An Approximate Picture", h. 754; Heffening, Heffening, "Wakf", dalam First Encyclopaedia of Islam, 1913-1936, (Leiden-New YorkKoln : EJ. Brill, 1993,. VIII: 1103. 
tanah negara (sawafi dan harta hak milik khalifah lainnya yang dapat digunakan bagi keperluan pribadinya (mustakhlass. Harta ini dikelola oleh pejabat yang disebut Sahib ad-Diya'.37

1. pemasukan

Wajib Pajak yang muslim dikenakan zakat yang dikumpulkan dalam bentuk uang tunai, hasil peternakan dan hasil pertanian. Zakat hasil pertanian (usyr dikenakan pada tanaman dan buah yang dapat disimpan dan tahan lama seperti gandum, biji-bijian, anggur dan kurma. Sementara zakat hewan (sadaqa dihitung berdasarkan jumalah hewan yang dimiliki. 38

Zakat yang masuk dalam bait muslim memeang masih menjadi perdebatan, namun sejarah Andalus telah memihak pada satu sisi yang didukung oleh ibn Hazm. Ibn Arabi, ulama Andalus juga mengungkapkan yang sama dengan alas an penguasaaan informasi yang luas dari pemerintah daripada sector masayarakat dalam memetakan kemiskinan yang ada di Negara. Mekanisme distribusi yang terencana dan terpadu ini tidak dapat dilakukan oleh sektor privat mengingat informasi mengenai kemiskinan disesuaikan dengan kepuasan dan manfaat yang dapat diperoleh dari pembayaran zakat serta kurang memperhatikan dampak sosial. Mekanisme privat mengabaikan perlunya pengawasan terhadap keseimbangan instrumen pengentasan kemiskinan ini dengan kebijakan lain yang ditujukan untuk kesejahteraan masyarakat ataupun sektor yang tidak berhubungan langsung dengan kebutuhan masyarakat. Keterbatasan sektor privat ini tercermin pada pandangan beberapa ulama fiqih yang berkeberatan terhadap dominasi pemerintah dalam mekanisme zakat. Ibn Arabi membolehkan muzakki menentukan mustahik, Ibn Qudamah lebih keras menyuarakan kepentingan muzakki agar zakat diberikan kepada mustahik yang dikehendakinya. Hal itu dimaksudkan agar muzakki dapat

37Ibid., h. 104; Chalmeta, “An Approximate Picture”, II: 749.

${ }_{38}^{8}$ Menurut Calmetta, zakat yang menjadi kewajiban pajak kepada pemerintah hanya pada dua obyek tersebut sementara yang lain diberikan langsung kepada yang berhak. Hal ini dikarenakan Harta zakat dibagi menjadi dua, dahiri dan batini. Pemerintah hanya wajib menarik zakat untuk mal dahiri. Chalmeta, "An Approximate" h. 741, 'Ali 'Abd ar-Rasul, al-Mabadi' al-Iqtisadiyyah al-Islamiyyah fi al-Islam wa al-Bina' al-iqtisadi li ad-Daulah al-Islamiyyah, (ttp.: Dar al-Fikr al-'Arabi,tt. h. 328; al-Farra'i, al-Ahkam as-Sultaniah, h. 45-46. 


\section{F. Setiawan Santoso}

merasakan manfaat langsung dari zakat yang bayarkan. Ia terbebas dari kewajiban zakat tanpa kekhawatiran dari perbuatan khianat dan dapat mempererat tali persaudaraan dengan mustahik yang telah dikenal. Ia selanjutnya menegaskan bahwa hal itu tidak bisa terjadi apabila zakat dibayarkan kepada pemerintah. Pemerintah dianggap tidak mampu menjamin para amil memberikan zakat kepada mustahik yang diketahui oleh muzakki.39

Pemasukan selain zakat adalah Kharaj. pajak tanah yang dikenakan bagi warga non muslim yang mengusahakan tanah pertanian, sementara bagi mereka yang tidak bertani dikenakan pajak sesuai dengan profesinya.40 Selain Kharaj, mereka wajib membayar jizyah yang besarannya diatur dalam kebijakan pemerintah. Pajak ini merupakan pajak perlindungan (poll tax, ${ }^{41}$ dan dikenakan hanya bagi laki-laki non muslim yang sudah dewasa. Wanita, pemimpin agama dan anak-anak tidak punya kewajiban membayarnya.42 Di Andalusia, perkembangan jumlah pajak kharaj dan jizyah semakin sedikit karena banyak warga pribumi yang beralih muslim (muwallad. Selain itu, lapangan ekonomi yang dikuasai oleh non muslim bukan lagi bidang agrobisnis dan beralih ke bidang industri perdagangan yang berada di wilayah perkotaan. 43

Sedangkan ganimah adalah harta rampasan perang yang diperoleh dari kerajaan Nasrani yang ditaklukan. Sebagian darinya dibagikan kepada anggota pasukan seperti barang-barang yang dapat dipindahkan dan sebagian lainnya dibawa ke bait al-mal sedang tanah dibagi menjadi milik bait al-mal dan negara (mal khas. Hingga masa dinasti Amirid (397

39Yusuf al-Qardawi, Fiqh az-Zakat, terj. Didin Hafiduddin dkk., (Jakarta: Litera Antar Nusa, 1993, II: 520.

${ }^{40}$ Hasanuz Zaman, SM, Economic Functions of Islamic State: The Early Experience, (Leicester: The Islamic Foundation, 1991M/1441H, h. 208

41Selain pajak perlindungan, jizyah adalah bukti ketaatan non muslim kepada kepemimpinan muslim dan sesuai dengan kandungan ayat at-Taubah (6: 29, jizyah ini dimaksudkan untuk merendahkan dan perlakuan diskriminatif bagi kelompok mereka (wa hum sagirun, Ibid., h. 208; Ziaul Haque, Landlord and Peasant in Islam, A. Study of Legal Doctrine Muzara'ah or Sharecropping, (Delhi: Idarat Adabiyyat Delli, 1985, h. 230.

${ }^{42}$ Umar ibn Khattab menghubungkan kedewasaan dalam penarikan jizyah dengan cukuran kumis dan jenggot, Ibid.

43 Imaduddin, Political History, h. 328 
H/1005 M, catatan sejarah masih menyebut ekspansi Andalusia ke kerajaan Nasrani sekitarnya. 44

Pemasukan bait al-mal yang signifikan didapat dari pajak importeksport (usyr karena letak geografisnya yang mendukung optimalisasi dari sektor ini.45 Hal itu diketahui dari berbagai macam jenis pajak yang ditetapkan darinya, seperti mukkus, ${ }^{46}$ tarif dan a'syar as-sufun. Mukkus ditujukan bagi barang dagangan ekspor atau import,47 tarif dibebankan kepada para pedagang Prancis yang masuk Andalusia dari ujung barat. Sementara kapal niaga yang masuk atau keluar melalui selat Gibraltar ditarik usyr secara berbeda. 48

Sistem distribusi yang ditawarkan oleh Ibn Hazm berdasarkan syari'ah. Ia tidak ingin hal-hal yang menyebabkan pemerintah berbuat tidak adil dan menyebabkan penerima memakan harta secara batil. Maka instrumen yang telah disesuaikan dengan persyaratan dan prosedur yang disahkan syari'at. Ia tidak setuju instrumen jaminan sosial dengan memakai instrumen pajak baru karena hal itu tentu tidak sesuai syariah. Ia keberatan dengan penetapan pajak mukus yang dikelola oleh aparat Yahudi di masa dinasti Umayyah dan menyebutnya tidak sesuai nass. Dengan alasan sama, ia mengkritik pajak kepala yang yang dikenakan kepada umat muslim sama seperti bagi non-muslim (jizyah oleh Muluk Tawa’if. Menurutnya, perpajakan yang tidak sesuai syariah menyebabkan ketidakadilan. 49

2. Pengeluaran

Alokasi harta Allah bagi kepentinggan ummah di bait mal ditetapkan oleh pemerintah bagi peningkatan kesejahteraan masyarakat dan peningkatan pertumbuhan ekonomi di sektor privat. Pemerintah

44 Ibid.

45Phillip K. Hitti, History Of The Arabs From The Earlies Times To The Present, (London-Toronto-Melbourne, Macmillan, 1968), h. 527

${ }^{46}$ Sejarah mukkus atau maks tidak diketahui, tetapi pada masa khalifah 'Umar ibn Abd al-'Aziz pernah dihapus yang berarti pajak ini pernah diberlakukan sebelumnya. Zaman, Economic Functions, h. 307.

${ }^{47}$ Ar-Rasul, al-Mabadi' al-Iqtisadiyyah, h. 242

${ }^{48}$ Ibid.

49 Ibid., h. 104. Abu Layla, In Pursuit of Virtue, the Moral Theology and Psychology of Ibn Hazm al-Andalusi (384-456 AH/ 994-1064 AD, (London: TaHa Publisher Ltd., tt), h. 33 


\section{F. Setiawan Santoso}

dapat mengalokasikan asset ini untuk kepentingan produksi barang dan jasa publik yang tidak mungkin dapat dimanfaatkan untuk kepentingan pribadi seperti pembangunan fasilitas umum jalan, pasar dan masjid.50 Pemanfaatan semua sarana itu ditujukan untuk kepentingan publik dan bukan dikhususkan untuk orang-orang yang bersedia membayar saja, pemerintah tidak bisa mengagalkan atau menunda produksi dan distribusinya meski ada keluhan dari salah satu konsumennya. Hal itu dikarenakan tujuan dari suplai barang/jasa publik adalah kepuasan sosial, maka barang ini selalu tersedia bagi siapapun pada saat kapanpun dengan tingkat kepuasan dan manfaat yang sama tanpa menimbulkan kehawatiran akan kehabisan produk dan persaingan. Barang ini lebih bermanfaat dalam mekanisme terbuka untuk siapa saja daripada ditetapkan secara khusus melalui penetapan harga.

Alokasi harta ini ditetapkan oleh pemerintah bagi peningkatan kesejahteraan masyarakat dan peningkatan pertumbuhan ekonomi di sektor privat. Pemerintah dapat mengalokasikan asset ini untuk kepentingan produksi barang dan jasa publik yang tidak mungkin dapat dimanfaatkan untuk kepentingan pribadi seperti pembangunan fasilitas umum jalan, pasar dan masjid. ${ }^{11}$ Pemanfaatan semua sarana itu ditujukan untuk kepentingan publik dan bukan dikhususkan untuk orang-orang yang bersedia membayar saja, pemerintah tidak bisa mengagalkan atau menunda produksi dan distribusinya meski ada keluhan dari salah satu konsumennya. Hal itu dikarenakan tujuan dari suplai barang/jasa publik adalah kepuasan sosial, maka barang ini selalu tersedia bagi siapapun pada saat kapanpun dengan tingkat kepuasan dan manfaat yang sama tanpa menimbulkan kehawatiran akan kehabisan produk dan persaingan. Barang ini lebih bermanfaat dalam mekanisme terbuka untuk siapa saja daripada ditetapkan secara khusus melalui penetapan harga.

Meski demikian, pemerintah dapat melakukan produksi pada barang dan jasa yang disediakan pula oleh sektor privat, terutama pada produk-produk beresiko tinggi dengan nilai manfaat yang besar bagi

${ }^{50}$ Ibid.

${ }^{51}$ Ibid. 
kepentingan seluruh umat seperti tambang garam. ${ }^{2}$ Garam adalah kebutuhan pokok yang sangat diperlukan dalam pengelolaan pangan, namun produksinya tidak memberikan keuntungan rutin bagi pengelolanya dikarenakan sumber daya alam itu tidak dapat diolah kembali oleh manusia bila telah habis.

Usaha berisiko tinggi juga dapat ditinjau dari biaya produksi. Dalam mekanisme pasar yang sempurna, keputusan para pengusaha untuk meningkatkan biaya produksi mengikuti perkembangan harga barang di pasar untuk mendapatkan profit yang optimal, bila permintaan dan harga menaik, produksi barang/jasa ditingkatkan, keputusan yang berlawanan diambil bila permintaan terhadap barng-barang yang diproduksi mengalami penurunan. 53

Pada beberapa jenis kebutuhan masyarakat semisal pemanfaatan padang rumput bagi penggembalaan hewan ternak melalui hima ${ }^{44}$ ongkos produksi semakin menurun seiring dengan peningkatan manfaatnya bagi masyarakat, hal ini berdampak pada penurunan harga dan perolehan profit yang tidak seimbang. Karakter produk demikian ini merupakan kendala bagi para produsen untuk bersaing dalam mekanisme pasar yang sempurna agar mendapatkan keuntungan maksimal. Usaha di bidangbidang tersebut kemungkinan besar mengalami kerugian jika produksi barang dinaikkan hingga tingkatan optimal.

Pada era fitnah, semua pengeluaran khizanat al-mal telah difokuskan untuk kepentingan militer dan mengabaikan pos-pos pengeluaran lainnya seperti jaminan sosial. Seluruh pendapatan dibelanjakan untuk penambahan persenjataan dan gaji tentara reguler ataupun tentara bayaran yang bersedia berperang untuk khalifah. Pada pemerintahan Hisyam II kedua pada tahun 1010-1012 M, bait al-mal pernah kosong dan ia menjual koleksi perpustakaan negara sebagai solusi mengatasi krisis ini. Demikian pula, pada masa pemerintah khalifah terakhir dinasti Umayyah, kekayaan khizanat al-mal telah habis. Untuk

53M. Suparmoko, Keuangan Negara dalam Teori dan Praktek, (Yoyakarta: BPFE, 1990), h. 15

54 Ibn Hazm, al-Muhalla, VIII: 236 


\section{F. Setiawan Santoso}

mengisinya, khalifah menetapkan pajak bagi barang kebutuhan seharihari, dan menjual sebagian perabotan istana. Kebijakannya menimbulkan ketidaksenangan di kalangan ulama sehingga ia didesak untuk menyerahkan kekuasaannya kepada Dewan Negara.55

\section{E. Penutup}

Pemanfaatan mal Allah dalam bait mal telah memperjelas peran pemerintah sebagai sebagai pemegang mandat Hak Allah. Pemanfaatan Hak Allah selain memang untuk-Nya semata, juga diperluas bagi kemaslahatan umat secara bersama. Sistem jaminan social dalam Islam telah mengimplementasikan hal itu baik dalam fiqh muamalah maupun sejarah perekonomian pemerintahan Islam di Andalusia di era Fikih Klasik.

Penggunaan bait mal untuk jaminan social juga didasari dengan keharusan pemerintah terlibat dalam sistem jaminan sosial guna jaminan penegakan hukum di semua aspek kehidupan dan pemeliharaan stabilitas ekonomi dan politik. Peran tercemin tercermin dengan adanya institusi hisbah dan pegawainya yang disebut al-muhtasib (almotacen). ${ }^{6}$ Di Andalus, institusi ini bermula dari perlunya pengawas pasar dengan didirikannya Wali as-Suq atau Sahib as-Suq kemudian dirubah menjadi Muhtasib dengan perluasan fungsi dan kedudukannya setara dengan Qadi.57

Lembaga hisbah mempunyai peran yang tak kurang dalam sistem jaminan sosial. dalam jaminan sosial di Andalus. Pada Tahun 914 M Abdurrahman III mewajibkan sedekah dan mengeluarkan sebagian pendapatan lumbung negara bagi keluarga yang menderita akibat musim kering. Bagi lahan pertanian yang gagal panen, kharaj dan usyr dibebaskan sementara para tuan tanah diwajibkan memberikan keringanan bagi tenaga kerjanya. Hajibnya, Ahmad ibn Badr, diberi tugas

\footnotetext{
tt.), h. 207-208.

${ }^{56}$ Hitti, History of, h. 527

57 Imaduddin, Arab Muslim, h. 101.
} 
untuk meperhatikan keluarga-keluarga tersebut dan mendistribusikan sedekah dengan pengawasan petugas hisbah. ${ }^{8}$

Tugas utama hisbah dibidang ekonomi tidak akan terlepas dari nass. Hisbah yang merupakan implementasi dari prinsip al-amr bi alma'ruf wa an-nahy 'an al-munkar dimana prinsip itu di bidang ekonomi oleh Ibn Hazm berguna untuk;

a. Pemeliharaan kesatuan negara dengan terciptanya kasih sayang antar umat

b. Penegakan keadilan tanpa membiarkan seseorang mengambil hak orang lain dengan tidak semestinya.

c. Peningkatan kualitas moral ekonomi seperti pencegahan umat dari makanan yang tidak halal dan cara yang tidak benar. 59

Selain itu, negara sebagai stabilitator sosial dan politik juga diperlukan dalam jaminan sosial agar berjalan secara efisien dan terarah. Peperangan, pertikaian antar kelompok, dan politik yang tidak sehat menjadi kendala pelaksanaan jaminan sosial. Sejarah masa fitna Andalus membuktikan hal itu dimana semua kekuatan yang dimiliki termasuk kekayaan bait al-mal telah difokuskan demi mempertahankan kekuasaan melalui kekuatan militer sehingga aspek kenegaraan lainnya menjadi terbengkalai termasuk pelaksanaan jaminan sosial.

\section{Daftar Pustaka}

Abu Layla, In Pursuit of Virtue, the Moral Theology and Psychology of Ibn Hazm al-Andalusi (384-456 AH/ 994-1064 AD). London: TaHa Publisher Ltd., tt.

, "An Introduction to the Life and Work of Ibn Hazm." The Islamic Quaterly vol. XXIX no. 2, 1985/1405. hlm. 75-99

Al-Ansari, Muhammad ibn Ahmad ibn Abu Bakr ibn Farraj. Al-Jami' li Ahkam al-Quran. Kairo: Dar-asy-Sya'b, $1372 \mathrm{H}$.

Chapra, M. Umer. Islam and Economic Challenge. alih bahasa: Nur Hadi Ihsan

Al-Farra'i, Abu Ya'la Muhammad ibn al-Hassan. al-Ahkam as-Sultaniah. Beirut: Dar al-Fikr, 1406H/1968 M.

Al-Fath, Ahmad Abu. Kitab al-Mu'amalat fi asy-syariah al-Islamiyyah wa al-Qawanin al-Misriyyah. cet. 1, Mesir: Al-Busfur, 1913.

58Ibid., h. 105

59Abu Muhammad ibn 'Ali ibn Ahmad ibn Sa'id ibn Hazm. Al-Fisal fi al-Mulk wa al-Ahwa' wa an-Nihal, (ttp.: Matba'ah at-Tamaddun, 1321H, IV: 167. 
Fikri, 'Ali. Al-Mu'amalat al-Madiyyah wa al-Adabiyyah. cet. 1. Mesir: Mustafa al-Babi al-Halabi wa Auladah, 1938.

Al-Gazali, Muhammad ibn Muhammad. al-Mustasfa. Beirut: Dar al-Kutub al-'Ilmiyyah, $1413 \mathrm{H}$.

Hasb Allah, Ali. Usul at-Tasyri’ al-Islam. Mesir: Dar al-Ma'rifah, tt.

Hitti, Phillip K. History Of The Arabs From The Earlies Times To The Present, London-Toronto-Melbourne, Macmillan, 1968.

Ibn Hazm Abu Muhammad ibn 'Ali ibn Ahmad ibn Sa'id. Al-Fisal fi alMulk wa al-Ahwa' wa an-Nihal. ttp.: Matba'ah at-Tamaddun, $1321 \mathrm{H}$.

Abu Muhammad ibn 'Ali ibn Ahmad ibn Sa'id. al-Akhlaq wa as-Siyar Fi Mudawat an-Nufus. Beirut: Dar al-Kutub al'Ilmiyyah, $1985 \mathrm{M} / 1405 \mathrm{H}$. , Abu Muhammad ibn 'Ali ibn Ahmad ibn Sa'id. al-Ihkam Fi Usul al-'Ahkam. Kairo: Dar al-Hadis, 1404H. , Abu Muhammad ibn 'Ali ibn Ahmad ibn Sa'id. al-Muhalla. Beirut: Dar al-Afaq al-Jadidah, tt.

Ibn Mandur, Muhammad ibn Mukarram. Lisan al-'Arab. Beirut: Dar Sadir, tt.

Ibn Rusdi, Muhammad ibn Ahmad ibn Muhammad ibn Ahmad. Bidayah al-Mujathid wa Nihayah al-Muqtasid. Beirut: Dar al-Fikr,tt.

Imaduddin, SM. Arab Muslim Adminstration (622-1258). New Delhi: Kitab Bhavan, 1984 . Political History of Muslim Spain. Pakistan: Najmah Sons, tt.

Iqbal, Munawwawr. (Ed.). Distributive Justice and Need Fulfilment in an Islamic Economy, Leicester: The Islamic Foundation-International Institute of Islamic Economics, 1988/1408.

Jayyusi, Salma Khadra. (Ed.). The Legacy Muslim of Spain, Leiden: EJ. Brill, 1994.

Al-Jaziri, 'Abd ar-Rahman. Kitab al-Fiqh 'ala al-Mazahib al-Arba'ah. Libanon: Dar al-Fikr,t.t..

Kahf, Monzer. The Prinsciple of Socio Economic Justice in The Contemporary of Zakat. Jeddah : IRTI, tt..

. "The Performance Of the Institusion Zakat in Theory and Practice." makalah dalam Konferensi International on Islamic Economics Towards the $21^{\text {st }}$ Century di Kuala Lumpur -Malaysia tanggal 26-30 1999.

Karcic, Fikrec. "Applying The Shariah in Modern Societies, Main Development and Issues.” Islamic Studies vol. 140 Summer 2001 no. 2. hlm. 210-219.

Kertonegoro, Sentanoe, Jaminan Sosial, Prinsip dan Pelaksanaannya di Indonesia. Jakarta ; Mutiara Sumber Widya, 1987.

Mangkusoebroto, Guritno. Ekonomi Publik, Suatu Analisis Teoritis. Yogyakarta: PAU Studi Ekonomi Universitas Gadjah Mada, 1988.

Al-Mu'ti, Faruq 'Abdul. Ibn Hazm ad-Dahiri. Beirut: Dar al-Kutub al'Ilmiyyah, 1992M/1413H. 
Muhsin dan Fadillah Putra, Hukum dan Kebijkan Publik, Analisis atas Praktek Hukum dan Kebijakan Publik dalam Pembangunan Sektor Perekonomian di Indonesia. Malang: Averroes Press, 2002.

An-Nabhani, Muhammad Faruq, al-Ittijah- al-Ijtima’i fi at-Tasyri alIqtisad al-Islami. Beirut: Muassasah ar-Risalah, 1984/1404.

Ar-Rayyis, Muhammad Diya ad-Din. An-Nadariyyah a-Siyasah alIslamiyyah, alih bahasa: Abdul Hayyie al-Kattani dkk., Jakarta: Gema Insani Press, 2001

Sakhr (CDRom). al-Mausu'ah al-Hadis asy-Syarif, ed. II, Cairo: GISCO, 1995.

Santoso, F. Setiawan. Reformasi Ekonomi Berbasis Bagi Hasil Belajar Dari Sistem Ekonomi Sosialis. MUQTASID Jurnal Ekonomi Dan Perbankan Syariah IAIN SALATIGA, 193-207

SM, Hasanuz Zaman, Economic Function of an Islamic State, The Early Experience, Karachi: Islamic Foundation, 1991/1411.

Suparmoko, M. Keuangan Negara Dalam Teori dan Praktek, Yogyakarta: BP-FE, 1990.

Syararah, Abu Latif, Ibn Hazm Ra'id al-Fikr al-'Ilmi Beirut: Dar alMaktab at-Tijari li at-Taba 'ah wa an-Nasyr wa at-Tauzi’, t.t.

Asy-Syatibi, Abu Ishaq. al-Muwafaqat. Beirut: Dar al-Ma’rifah, tt.

Syufaat, Fikih Jaminan Sosial dalam pespektif Ibn Hazm (994-1064), Manahaij, Volume IX, Juni 2015, 111-122.

Yazwardi, Pengaruh Perubahan Sosial Terhadap Pemikiran Literalism Ibnu Hazm, AN NISA'A, Vol. 9, NO. 2, Desember 2014 : $61-80$

Wartini, Atik. Jaminan Sosial Dalam Pandangan Ibnu Hazm Dan Relevansinya Dengan Pengembangan Jaminan Sosial Di Indonesia, Hunafa: Jurnal Studia Islamika Vol. 11, No. 2, Desember 2014: 245-275. 
F. Setiawan Santoso 